\title{
Plant community functional shifts in response to livestock grazing in intermountain depressional wetlands in British Columbia, Canada
}

\author{
W. Marc Jones ${ }^{\mathrm{a}, *}$, Lauchlan H. Fraser ${ }^{\mathrm{b}}$, P. Jefferson Curtis ${ }^{\mathrm{a}}$ \\ ${ }^{a}$ Department of Chemistry, Earth and Environmental Sciences, University of British Columbia Okanagan, Kelowna, British Columbia, Canada V1V $1 V 7$ \\ ${ }^{\mathrm{b}}$ Department of Natural Resource Science, Thompson Rivers University, Kamloops, British Columbia, Canada V2C 5N3
}

\section{A R T I C L E I N F O}

\section{Article history:}

Received 9 November 2009

Received in revised form 2 October 2010

Accepted 2 October 2010

Available online $\mathrm{xxxx}$

\section{Keywords:}

Depressional wetlands

Disturbance gradient

Functional groups

Livestock grazing

Marsh

Wet meadow

\begin{abstract}
A B S T R A C T
Wetlands are ecologically and economically important ecosystems with high conservation value. Although wetland vegetation is strongly determined by abiotic factors, grazing disturbance may also be an important influence on this community. We evaluated the effects of livestock grazing on wetland vegetation in marsh and wet meadow zones in intermountain depressional wetlands in the southern interior of British Columbia, Canada. We sampled marshes and wet meadows in 36 wetlands along a grazing intensity gradient ranging from fully fenced and ungrazed wetlands to unfenced wetlands heavily grazed by livestock. The amount of bare ground was used as a surrogate measure of the intensity of livestock grazing. Vegetation community structure and composition was strongly associated with grazing intensity. Increased livestock grazing favored shorter-lived and smaller plants; conversely, the frequency of tall and rhizomatous species, which constitute the dominant plant species in these systems, declined with higher livestock use. The effects of grazing were more pronounced in the marsh than in the wet meadow. Associations between species richness and grazing differed between zones: native and exotic species richness showed a unimodal response in the marsh while in the wet meadow exotic richness increased and native richness showed no response. The relationship between exotic frequency and grazing was also inconsistent between zones, with a negative association in the marsh and a positive but weak association in the wet meadow. Grazing-related changes in vegetation along the grazing intensity gradient were substantial and may affect the habitat value of these wetlands for dependent wildlife such as breeding waterfowl.
\end{abstract}

(c) 2010 Elsevier Ltd. All rights reserved.

\section{Introduction}

Half of the world's land area is rangeland (Havstad, 2008), and grazing by domestic livestock is a substantial and pervasive land use throughout the world (Milchunas and Lauenroth, 1993; Diaz et al., 2007). The effects of livestock grazing on rangelands and riparian areas have been well studied. Livestock selectively remove biomass, trample vegetation, disturb and compact soil, and add nutrients, and grazing can significantly alter the structure, productivity, diversity, and plant competitive interactions of grazed ecosystems (Martin and Chambers, 2001; Kauffman et al., 2004; Frank, 2005; Manier and Hobbs, 2007).

Freshwater depressional wetlands often occur within a rangeland matrix, such as in the intermountain west and prairie pothole regions of North America. Freshwater wetlands provide important ecological and economic services, such as wildlife habitat, regulation of water regimes, filtration of polluted water, and production of forage (Mitsch and Gosselink, 2000) and are critically important

\footnotetext{
* Corresponding author. Tel.: +1 250852 6283; fax: +1 2508285450.

E-mail address: wmjones547@hotmail.com (W.M. Jones).
}

for breeding waterfowl and amphibians (Johnson et al., 2005; Piha et al., 2007). However, our understanding of the effects of livestock grazing on freshwater wetlands is limited, especially for the study area (Austin et al., 2007). A better understanding of how grazing affects vegetation (and thus wetland habitat) is an important step in determining tradeoffs between the ecological and economic services of wetlands and maintaining their biodiversity and productivity.

Several models have been proposed that predict vegetation community response to grazing with regard to simple functional attributes, including the generalized model (Milchunas et al., 1988; Milchunas and Lauenroth, 1993), competitor-stress tolerator-ruderal (CSR) model (Grime, 1977, 2001), and the range succession model (Dyksterhuis, 1949). These models predict that grazing will favor plant species with an annual life history, short canopy height, and (in the cases of the generalized and range succession models) a rhizomatous or stoloniferous root architecture. Empirical studies have largely validated these predictions in a variety of rangeland types (McIntyre et al., 1995; Diaz et al., 2001, 2007). Grazers preferentially forage tall, fast-growing, competitively dominant species (Fraser and Grime, 1999). Reduction of the 
dominant species through grazing can reduce the competitive advantage of these species and benefit shorter-statured, slowgrowing species as well as increase species richness and community diversity (Gough and Grace, 1998; Fraser and Grime, 1999). Grazing can also increase gaps in vegetation and reduce litter accumulation, and moderate grazing can thereby provide greater establishment opportunities for species with life histories, architectures, or dispersal strategies that allow them to exploit these gaps (van der Valk, 1986; Humphrey and Patterson, 2000; Bullock et al., 2001; Dorrough et al., 2004).

We examined the effects of livestock grazing on intermountain depressional wetlands to see if predictions of grazing models developed for rangelands could be extended to highly productive wetland systems that are subject to flooding stress not encountered in upland systems. We examined differences in the wetland vegetation community along a grazing intensity gradient and between wetland zones subject to different flooding regimes. We evaluated vegetation biomass and litter, species composition and richness, and frequency of functional groups.

We classified species into groups based on readily observable functional traits such as life history, architecture, height, growth form, and origin. Study wetlands are currently subject to pervasive grazing pressure but have a short evolutionary history of grazing (Daubenmire, 1970; Mack and Thompson, 1982) and are therefore likely to show a strong functional response to grazing (Milchunas and Lauenroth, 1993; Diaz et al., 2007). We expected annuals, short and rhizomatous species, and forbs to increase with increasing grazing intensity, perennials, medium, tall, and non-rhizomatous species to decrease with increasing grazing intensity, and the response of graminoids to be neutral.

Following Kantrud et al. (1989), we classified wetland vegetation into two zones: marsh (typically inundated for much of the growing season and characterized by dense stands of tall emergent vegetation) and wet meadow (temporarily flooded during the growing season and dominated by smaller graminoids). Given the abundance of emergent vegetation, competition for light may be more intense in the marsh, and we expected the effects of grazing to be more pronounced there, which would be consistent with predictions of the CSR and generalized models. The marsh zone is subject to greater flooding stress but is less hydrologically variable (Kantrud and Stewart, 1977) and less species rich (Keddy, 2000) than the wet meadow.

\section{Methods}

\subsection{Study Sites}

We sampled 36 depressional wetlands from the southern interior of British Columbia, Canada, near the city of Kamloops. Twenty-five wetlands were sampled in June and July of 2006 and the remaining eleven were sampled in July and early August of 2007. We selected sites from wetlands that are part of a long-term (20 years) waterfowl breeding pair survey conducted by Ducks Unlimited Canada and the Canadian Wildlife Service. Sample wetlands were either semipermanently or permanently flooded (except for two sites that were seasonally flooded) and ranged from oligo- to mesosaline. Sites encompassed a grazing disturbance gradient from fully fenced and ungrazed to unfenced and heavily grazed by livestock (pasture-level stocking densities at grazed sites ranged from 0.4 to 2 cattle/ha). Fenced sites included one fully fenced and three partially fenced wetlands that have been managed as cattle exclosures for approximately 15 years. Common wet meadow species include Carex praegracilis (field sedge), Hordeum jubatum (foxtail barley), and Juncus balticus (Baltic rush); typical marsh species include Bolboschoenus maritimus (seacoast bulrush), Schoenoplectus acutus and Schoenoplectus tabernaemontani (hard- and soft-stemmed bulrush), and Puccinellia nuttalliana (Nuttall's alkaligrass).

\subsection{Wetland vegetation}

We sampled vegetation along six transects systematically placed around the wetland equidistant from one another. We placed transects parallel to the hydrological gradient and ran from the aquatic-emergent vegetation boundary in the marsh zone to the wetland-terrestrial vegetation boundary in the wet meadow zone. Transect lengths varied depending on the width of these zones, from approximately $10 \mathrm{~m}$ to $100 \mathrm{~m}$. We delimited wetland zones based on the dominant vegetation of each wetland using species-hydrology associations summarized in Kantrud et al. (1989). We measured plant species frequency of occurrence in 60 $0.5-\mathrm{m}^{2}$ quadrats placed equidistant along transects (30 in each zone). Species nomenclature followed Douglas et al. (1998-2002).

We separately sampled aboveground biomass and litter from the middle of the wet meadow and marsh zones at each vegetation transect (six samples per zone per site) using $0.25-\mathrm{m}^{2}$ quadrats. We clipped aboveground biomass to a height of $1 \mathrm{~cm}$. Biomass and litter samples were oven-dried at $65{ }^{\circ} \mathrm{C}$ for at least $72 \mathrm{~h}$ to a constant dry mass.

\subsection{Plant traits}

We evaluated nine non-mutually exclusive functionally defined groups. These were based on species' life history (annual or biennial, perennial), root architecture (rhizomatous, non-rhizomatous), canopy height (short, medium, tall), and growth form (forb, graminoid). We also evaluated species of exotic origin. The rhizomatous category included species with rhizomes and stolons as well as creeping species that develop nodal roots. Breaks for the height category were $<40 \mathrm{~cm}$ (short), between 40 and $80 \mathrm{~cm}$ (medium), and $>80 \mathrm{~cm}$ (tall) (Diaz et al., 2001; Pykälä, 2004). All species classifications were based on Douglas et al. (1998-2002). To measure functional group similarity, we calculated the proportion of species shared between each pair of groups using the Jaccard coefficient of community.

\subsection{Grazing intensity}

We measured bare ground and soil bulk density at each wetland. For each wetland zone, bare ground was calculated as the mean number of vegetation quadrat corners that intersected bare ground ( $n=30 /$ zone), while soil bulk density was calculated for each wetland ( $n=6 /$ site). Where quadrats were inundated, a rod projected vertically from the quadrat corner to the substrate was used. The site-level measure of bare ground was highly correlated with soil bulk density $(r=0.83)$, and we used bare ground as our indicator of grazing intensity within each wetland zone (Greenwood and McKenzie, 2001; Hendricks et al., 2005; Manier and Hobbs, 2007). Although bare ground is used as a surrogate measure of grazing intensity, it can also be indicative of mechanical disturbance through hoof shear and trailing (M. Jones, personal observation). To improve the interpretability of this measure, it was rescaled so that it ranged from 0 to 100 .

\subsection{Statistical analysis}

We used a Wilcoxon rank sum test to compare whether bare ground was different between the marsh and wet meadow zones and whether aboveground biomass was different between the zones at wetlands with no measurable grazing pressure (bare ground $=0$ ). We used linear regressions to model the relationships 
of marsh- and wet meadow-level mean biomass and litter to grazing intensity ( $n=35$ for marsh, $n=36$ for wet meadow). Assumptions of linear regression (normal distribution of errors, constant variance) and the effect of influential data were checked by examining plots of residuals against fitted values, residuals against each datum's leverage, and quantile-quantile plots of residuals against quantiles.

We used an indirect ordination technique, nonmetric multidimensional scaling (NMDS) to examine associations between plant community composition and grazing intensity. NMDS was calculated based on a Bray-Curtis dissimilarity matrix of vegetation frequency data aggregated to the level of wetland zone using the metaMDS routine in the vegan package for the R statistical environment (Oksanen et al., 2008; R Development Core Team, 2008). This routine chooses multiple random starts with Procrustes rotations to find a global (vs. local) NMDS solution and uses principal components analysis to rotate the final solution so that the first axis explains the greatest variation in the data. NMDS was run for $k=2-4$ dimensions. The optimal number of dimensions was selected by examining a scree plot of stress vs. dimensionality and choosing the dimension number at the main inflection point (i.e., where the reduction in stress accompanying increased dimensionality was minimal).

Associations between plant functional groups, richness of native and exotic species, and grazing intensity were evaluated with generalized linear models in R. We modeled the probability of occurrence of each functional group in each wetland zone as well as overall species richness in each wetland zone conditional to the amount of bare ground ( $n=35$ for marsh, $n=36$ for wet meadow). We used quasi-binomial models with a logit link function to evaluate functional group response and quasi-Poisson models with a log link function to evaluate the response of species richness. Diagnostic plots of the models similar to the ones described previously were examined to verify model assumptions of distribution and constant variance. We included a quadratic term for bare ground in models to account for a unimodal response to grazing (Hobbs et al., 1996; Fensham et al., 1999; Grime, 2001). We evaluated the importance of the quadratic term using F-ratio tests and retained it in the models only where it was significant at $\alpha=0.05$.

\section{Results}

Bare ground was not different between the marsh and wet meadow $(W=608, p=0.97)$. Mean values of the bare ground index were $34.2 \pm 34.4(\mathrm{SD})$ in the marsh and $31.4 \pm 28.8(\mathrm{SD})$ in the wet meadow. Aboveground vegetation biomass and litter were significantly negatively associated with bare ground in both the marsh (biomass: $F_{1,33}=44.7, R^{2}=0.58, p<0.0001$, litter: $F_{1,33}=$ 16.0, $R^{2}=0.33, p=0.0003$ ) and wet meadow zone (biomass: $F_{1,34}=22.9, R^{2}=0.40, p<0.0001$, litter: $F_{1,34}=15.5, R^{2}=0.31, p=$ $0.0004)$. In the marsh zone, a 10 unit increase in the bare ground index was associated with a $42.2 \pm 12.9 \mathrm{~g} / \mathrm{m}^{2}(95 \% \mathrm{CI}, n=35)$ decrease in aboveground biomass and a $21.9 \pm 11.2 \mathrm{~g} / \mathrm{m}^{2}(95 \% \mathrm{Cl}$, $n=35$ ) decrease in litter. In the wet meadow zone, a 10 unit increase in bare ground was associated with a $30.8 \pm 13.1 \mathrm{~g} / \mathrm{m}^{2}$ $(95 \% \mathrm{CI}, n=36)$ decrease in biomass and a $23.2 \pm 12.0 \mathrm{~g} / \mathrm{m}^{2}(95 \%$ $\mathrm{CI}, n=36)$ decrease in litter. At sites with no measured livestock grazing $(n=7)$, mean aboveground biomass was higher in the marsh $\left(507 \pm 185 \mathrm{~g} / \mathrm{m}^{2}\right.$ (SD)) than in the wet meadow (348 \pm $\left.68 \mathrm{~g} / \mathrm{m}^{2}(\mathrm{SD})\right)$, although this difference was not statistically significant $(W=37, p=0.13)$.

Ordination results for wetland vegetation showed a high level of separation between wetland zones as well as clustering along the grazing intensity gradient (Fig. 1). The greatest variation

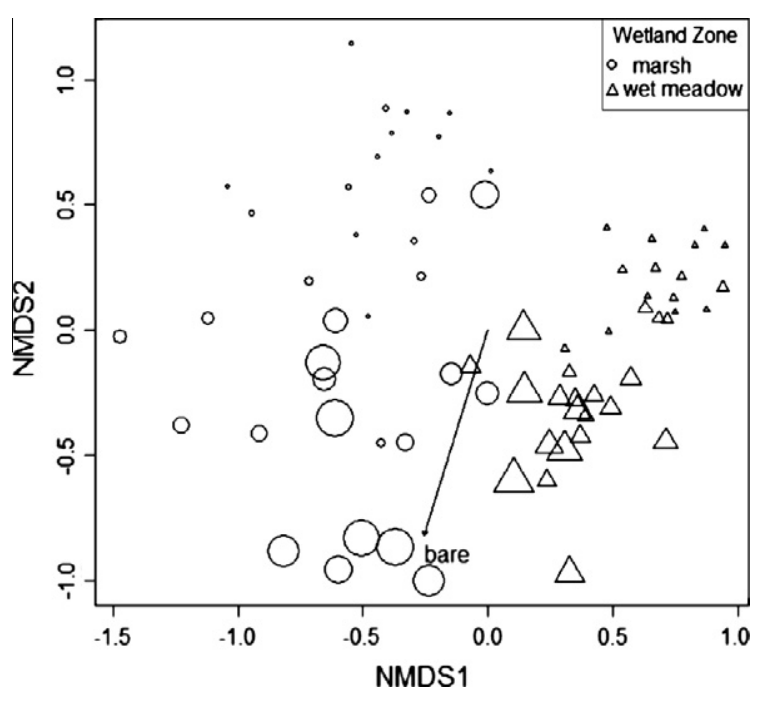

Fig. 1. Unconstrained ordination results for wetland vegetation (stress-based $R^{2}=0.96$ ). Marshes and wet meadows are represented by $\bigcirc$ 's and $\Delta$ 's, respectively. Symbol size is scaled by grazing intensity with larger symbols representing greater amounts of bare ground. Vector label refers to bare ground (bare); vector length corresponds to the strength of correlation.

among samples was explained by the first axis (NMDS 1) and appeared to reflect wetland hydrology given the strong separation between marsh and wet meadow zones along this axis. The second axis (NMDS 2) was associated with grazing intensity, which was strongly correlated with bare ground $(r=-0.73)$. Although grazing appeared to be an important factor in structuring the vegetation community in both the marsh and wet meadow, this pattern is weaker for the marsh community, which was less clustered in ordination space, than for the wet meadow.

Although functional groups were not mutually exclusive in all cases, the proportion of shared species exceeded 50\% for only two group comparisons. Perennial and rhizomatous groups shared $69 \%$ and $60 \%$ of species in the marsh and wet meadow zones, respectively, and annual and non-rhizomatous groups shared $61 \%$ and $51 \%$ of species.

The frequency of occurrence of most functional trait-based groups evaluated was strongly associated with the amount of bare ground, although the deviance explained (analogous to $R^{2}$ for linear models) for some functional groups was not high (Table 1). Many groups had a consistent response to bare ground in both the marsh and wet meadow zones. The predicted probability of encountering a non-rhizomatous or short species in a quadrat were positively associated with bare ground in both zones, rhizomatous and tall species were negatively associated with bare ground in both zones, and graminoids and perennial species had no statistically significant association with bare ground in either zone (Fig. 2). Forbs and annual species showed a unimodal response to bare ground in the wet meadow, with frequencies of occurrence highest at intermediate levels of bare ground, but were positively associated with bare ground in the marsh (Fig. 2). In contrast, plant species of medium height and exotic species were positively associated with bare ground in the marsh zone but negatively associated in the wet meadow zone (Fig. 2). The richness of both native and exotic species exhibited a unimodal response in the marsh zone, with the greatest numbers of species occurring at intermediate levels of bare ground. Conversely, in the wet meadow zone, the richness of exotic species was positively associated with bare ground but there was no statistically significant association between native richness and bare ground (Fig. 2). It should be noted that for both forbs and exotic species in the wet meadow, the site with the highest measure of bare ground exerted a strong 
Table 1

Deviance explained, df, and significance of bare ground for generalized linear models describing the association of plant functional group frequency and species richness with bare ground in the marsh and wet meadow zones ( $n=35$ for marsh, $n=36$ for wet meadow).

\begin{tabular}{|c|c|c|c|c|c|c|c|}
\hline \multirow[t]{2}{*}{ Functional group/richness } & \multirow[t]{2}{*}{ Zone $^{\mathrm{a}}$} & \multirow{2}{*}{$\begin{array}{l}\text { Deviance } \\
\text { explained }\end{array}$} & \multirow[t]{2}{*}{ df } & \multicolumn{2}{|c|}{ Bare ground } & \multicolumn{2}{|c|}{ Bare ground ${ }^{\mathrm{b}}$} \\
\hline & & & & $t$ & $P$ & $t$ & $P$ \\
\hline \multirow[t]{2}{*}{ Forb } & M & 0.31 & 1.34 & 3.72 & $<0.001$ & & \\
\hline & W & 0.20 & 2.34 & 2.24 & 0.032 & -2.57 & 0.015 \\
\hline \multirow[t]{2}{*}{ Graminoid } & M & 0.12 & 1.34 & -1.68 & 0.100 & & \\
\hline & W & 0.24 & 1.35 & -1.88 & 0.069 & & \\
\hline \multirow[t]{2}{*}{ Annual } & M & 0.49 & 1.34 & 5.19 & $<0.001$ & & \\
\hline & W & 0.33 & $2 ., 33$ & 3.84 & $<0.001$ & -3.18 & 0.003 \\
\hline \multirow[t]{2}{*}{ Perennial } & M & 0.12 & 1.34 & -1.50 & 0.140 & & \\
\hline & W & 0.24 & 1.35 & -1.50 & 0.142 & & \\
\hline \multirow[t]{2}{*}{ Rhizomatous } & M & 0.39 & 1.34 & -3.74 & $<0.001$ & & \\
\hline & W & 0.59 & 1.35 & -5.10 & $<0.001$ & & \\
\hline \multirow[t]{2}{*}{ Non-rhizomatous } & M & 0.53 & 1.34 & 4.93 & $<0.001$ & & \\
\hline & $\mathrm{W}$ & 0.52 & 1.35 & 4.99 & $<0.001$ & & \\
\hline \multirow[t]{2}{*}{ Short } & M & 0.49 & 1.34 & 5.03 & $<0.001$ & & \\
\hline & $\mathrm{W}$ & 0.44 & 1.35 & 4.22 & $<0.001$ & & \\
\hline \multirow[t]{2}{*}{ Medium } & M & 0.32 & 1.34 & 3.73 & $<0.001$ & & \\
\hline & $\mathrm{W}$ & 0.57 & 1.35 & -5.17 & $<0.001$ & & \\
\hline \multirow[t]{2}{*}{ Tall } & M & 0.50 & 1.34 & -4.68 & $<0.001$ & & \\
\hline & W & 0.21 & 1.35 & -3.07 & 0.004 & & \\
\hline \multirow[t]{2}{*}{ Exotic } & M & 0.12 & 1.34 & 2.19 & 0.036 & & \\
\hline & W & 0.12 & 1.35 & -2.08 & 0.045 & & \\
\hline \multirow[t]{2}{*}{ Exotic richness } & M & 0.22 & 2.33 & 3.08 & 0.004 & -2.73 & 0.010 \\
\hline & W & 0.17 & 1.35 & 2.63 & 0.013 & & \\
\hline \multirow[t]{2}{*}{ Native richness } & M & 0.24 & 2.33 & 2.73 & 0.010 & -2.22 & 0.034 \\
\hline & W & 0.06 & 1.35 & -1.43 & 0.160 & & \\
\hline
\end{tabular}

\footnotetext{
a $M=$ marsh, $W=$ wet meadow (bare ground).
}

b Is the quadratic term for bare ground.

influence on the model fit. When this site was removed from the analysis, the relationships between the functional groups and bare ground were no longer statistically significant. Given that we have no biological basis for the removal of this site and that it represents the most extreme end of the grazing intensity gradient, we have retained it in the analysis.

\section{Discussion}

We found that livestock grazing strongly affects the richness, structure, and composition of wetland vegetation communities in intermountain depressional wetlands. Community structure was more variable in the marsh zone compared to the wet meadow regardless of grazing intensity. Our results were largely consistent with model predictions and previous studies (Dyksterhuis, 1949; Grime, 1977; Milchunas et al., 1988; Diaz et al., 2007). The frequency of annuals, forbs, and short species increased with grazing intensity, although the frequency of annuals and forbs in the wet meadow zone decreased at high levels of bare ground. Tall and medium height species decreased with grazing intensity (the latter only in the wet meadow), and graminoid frequency was not associated with grazing intensity. Contrary to our expectations and previously developed models, perennial species showed no response to grazing intensity, rhizomatous species were negatively associated with grazing, and non-rhizomatous were strongly positively associated with grazing.

Grazing-vegetation models were largely developed for grasslands, and although the generalized and CSR models (Milchunas et al., 1988; Milchunas and Lauenroth, 1993; Grime, 2001) as well as a global review of previous research (Diaz et al., 2007) have incorporated productivity into model predictions, these models have not been applied to such highly productive systems as wetlands. Our results show that many model predictions are applicable to wetlands, which tend to be more productive than grasslands as well as subject to flooding stress. In general, the response of functional groups that were expected to be positively associated with grazing intensity was more consistent with model predictions than were functional groups that were expected to be negatively associated with grazing.

There are several mechanisms whereby ungulate grazing can affect plant communities. Grazers can remove biomass, physically damage plants by trampling, and create gaps, as well as alter plant reproductive output, competitive interactions, and nutrient dynamics. In the wetlands studied, mechanisms that affect plant competition and colonization may be of primary importance. Vegetation of ungrazed depressional wetlands is typically relatively species poor and is characterized by dense stands of tall, clonal, competitively dominant species. Competition for light is likely to be an important constraint in such a system (Twolan-Strutt and Keddy, 1996; Geho et al., 2007), as is the ability to successfully colonize gaps (Carlyle and Fraser, 2006). This is attested by the near-ubiquity of tall and rhizomatous species at ungrazed sites in the study.

Grazing-mediated changes in competitive interactions and shifts in dominance have been documented in wetlands (Ausden et al., 2005), and clipping has been shown to significantly affect biomass, reproductive output, and juvenile growth of wetland plants (Crosslé and Brock, 2002; Hayball and Pearce, 2004). Grazing-associated reductions in aboveground biomass and litter observed in this study as well as increases in bare ground from trampling are likely to alter competitive outcomes and provide greater establishment opportunities. Because the frequency of occurrence of both tall and rhizomatous species declined with increasing grazing intensity, it is likely that the reduction in 
Forb

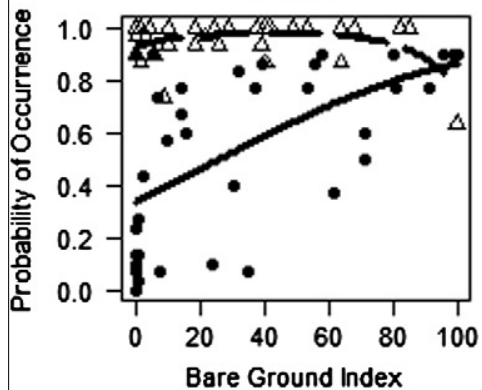

Perennial

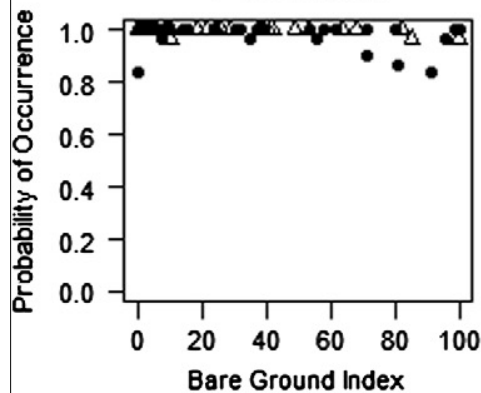

Short

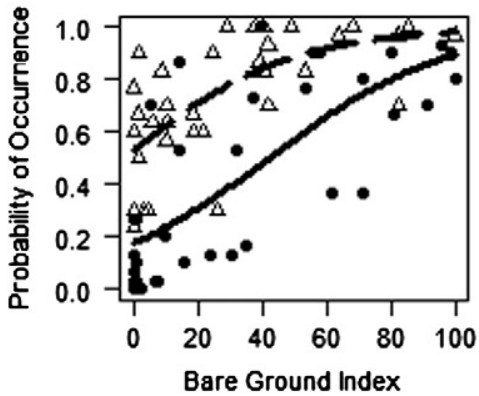

Exotic

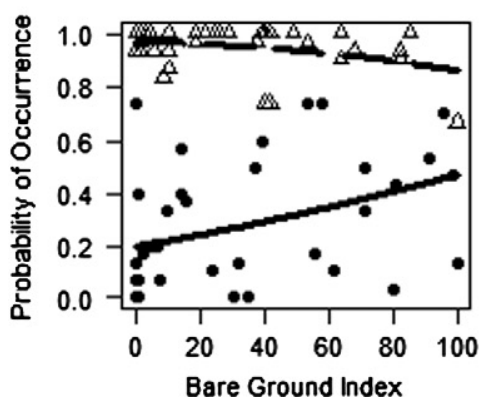

Graminoid

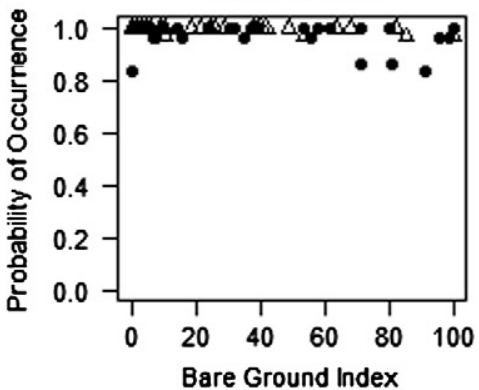

Rhizomatous

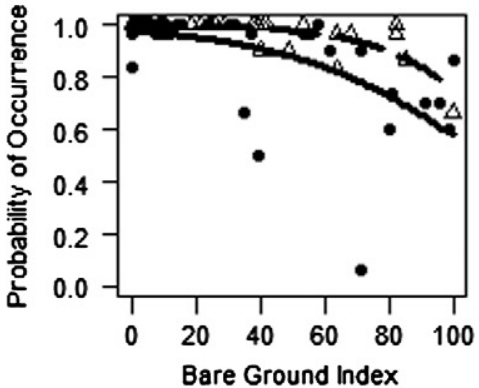

Medium

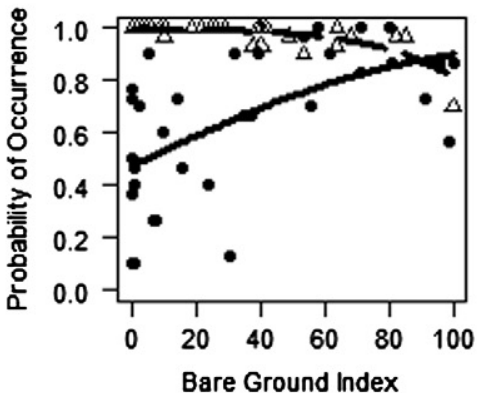

Exotic Richness

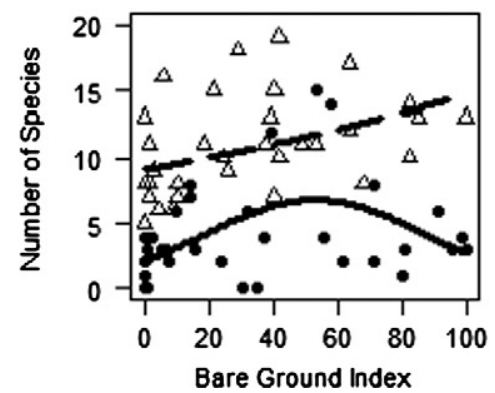

Annual

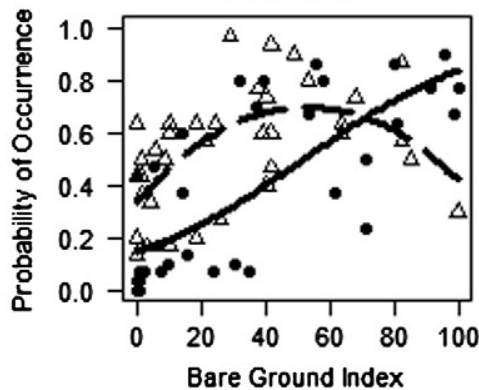

Non-rhizomatous

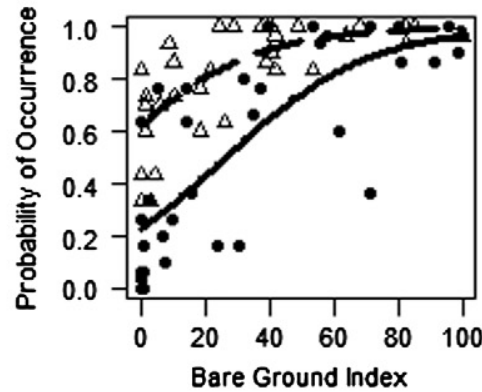

Tall

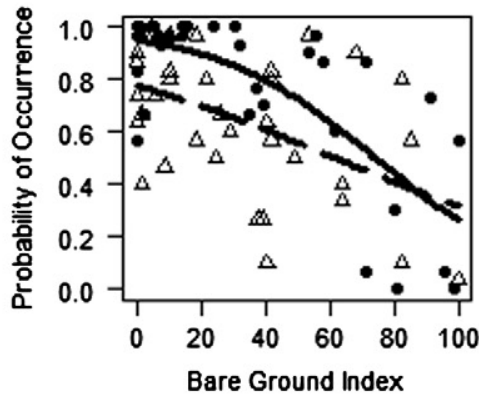

Native Richness

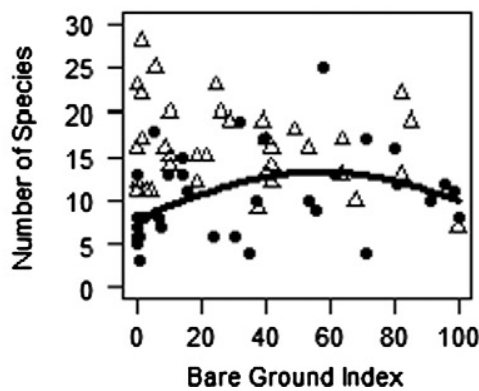

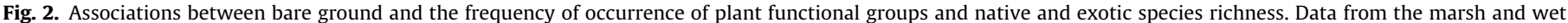

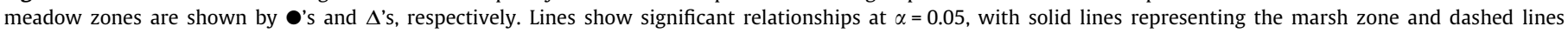
representing the wet meadow zone.

frequency of these groups, which contain many of the competitively dominant species, would provide opportunities for less competitive species, especially if they were unpalatable or had attributes that allowed them to either avoid or tolerate grazing pressure. This may explain why the non-rhizomatous functional group, which shared many species with the annual group, was positively associated with grazing intensity.

Perennials and graminoids showed no response to grazing intensity. Both these groups are ubiquitous in the study wetlands and encompass species with very different responses to grazing. Common members of both groups were P. nuttalliana and H. jubatum, which were positively associated with grazing, and S. acutus and $J$. balticus, which were negatively associated with grazing. For the study wetlands, these functional groups may be too general to make consistent predictions of their response to grazing intensity. This was expected for graminoids but not for perennials, which other studies have consistently found to be negatively associated with grazing (Diaz et al., 2007). 
The relationship between species richness and livestock grazing was not consistent between zones. In the marsh zone, the relationship was hump-shaped for both native and exotic species, while in the wet meadow it was positive for exotic species but there was no effect on native species. It is a well established hypothesis that species richness will be maximized at intermediate levels of disturbance (Grime, 1973; Connell, 1978; Pacala and Crawley, 1992); however, both productivity and species pools can influence this pattern. Species richness and disturbance have been shown to be positively associated in highly productive communities and negatively associated in communities with low productivity (Grime, 1973; Olff and Ritchie, 1998; Kondoh, 2001; Frank, 2005). The relative size of a community's regional species pool (i.e., the number of species capable of living within that community) can also strongly influence species richness (Zobel, 1997; Grace, 2001). Productivity, as measured by aboveground biomass, was not significantly different between the marsh and wet meadow zones at ungrazed sites. The number of species sampled from the marsh $(n=82)$ was substantially less than the number sampled from the wet meadow $(n=127)$, implying that the regional species pool of marsh species is more restricted. It is possible that the decline in species richness associated with very high levels of bare ground may reflect the more limited pool of available species in this community.

Similarly, the relationship between the frequency of exotic species and grazing was not consistent between the marsh and wet meadow zones. Although exotic species are often positively associated with grazing (McIntyre and Lavorel, 1994; Rusch and Oesterheld, 1997; Diaz et al., 2007), this is not always the case (Marty, 2005), and whether grazing facilitates or inhibits exotic species may be contingent on specific community and species dynamics. In the wet meadow, exotic species occurred at very high frequencies at undisturbed wetlands, and the three most abundant species, Poa pratensis (Kentucky bluegrass), Sonchus arvensis (field sowthistle), and Agrostis stolonifera (redtop), were tall and competitively dominant. In contrast, in the marsh, exotic species included higher numbers of forbs, annuals, and short species.

Marsh zone vegetation in this study was both more species poor and more dissimilar among wetlands than wet meadow vegetation. The response of many functional groups was largely consistent with grazing models and was strongly directional in response to grazing intensity in both zones; however, change in community structure was more variable in the marsh than in the wet meadow. Thus grazing exerted a strong filter on functional composition in both zones but had a weaker influence on overall species composition in the marsh than in the wet meadow.

Differences in richness and functional group frequency between the marsh and wet meadow zones may have to do with the interaction of grazing with hydrology or with differential hydrological constraints between the two zones. Vegetation zonation in these wetlands is determined by water depth through species-specific effects on seed germination, seedling survival, and adult mortality (van der Valk and Welling, 1988). Water depth acts as a very strong filter on wetland vegetation regeneration (van der Valk, 1981; Weiher and Keddy, 1995), and the marsh vegetation species pool may be limited due to constraints caused by flooding. It is possible that the greater hydrologic stability and more limited species pool of the marsh provide for fewer regeneration opportunities and a stronger founder effect which leads to greater community dissimilarity.

\subsection{Management implications}

Compositionally and functionally, wetland vegetation changed substantially along the observed livestock grazing gradient. These changes can have broader implications for the habitat and biodi- versity values of these wetlands. Decreases in biomass and the frequency of tall species, which comprise the dominant species in these wetlands, can adversely affect the habitat value of these wetlands for wetland-associated wildlife. Both breeding waterfowl and amphibians are sensitive to livestock grazing in wetlands (Kirsch, 1969; Klett et al., 1988; Belanger and Picard, 1999; Schmutzer et al., 2008). For the study wetlands, the intensity of livestock grazing was negatively associated with waterfowl breeding use, especially of dabbling ducks, which are more likely to use emergent vegetation as escape cover ( $\mathrm{M}$. Jones, unpublished data). Compared to ungrazed wetlands, grazing effects on wetland vegetation appeared to occur at even low levels of grazing intensity. However, low intensity grazing is much more likely to be compatible with the management of these wetlands for conservation values. Further work is needed to link the observed grazing intensity gradient with stocking rates and seasonality of livestock use. These linkages may better direct wetland management.

\section{Role of funding sources}

Funding was provided by Ducks Unlimited Canada Western Region office and the Institute for Wetlands and Waterfowl Research as well as the British Columbia Ministry of Forests and Range Forest Science Program. In addition, M. Jones was supported by the Natural Sciences and Engineering Research Council of Canada Industrial Postgraduate Fellowship. These sponsors had no involvement in the study design, data collection or analysis, writing or submission of this manuscript.

\section{Acknowledgments}

We thank Bruce Harrison with Ducks Unlimited Canada for his collaboration on this project. For field assistance we thank Montana Burgess, Eleanor Bassett, Jessica Gosling, Anna Maria Pellett, and Amy Bitz. We also thank three anonymous reviewers for constructive comments that greatly helped to improve the manuscript. Funding was provided by grants from Ducks Unlimited Canada's Institute for Wetland and Waterfowl Research and the British Columbia Ministry of Forests and Range Forest Science Program. M. Jones was also supported by an NSERC Industrial Postgraduate Scholarship.

\section{References}

Ausden, M., Hall, M., Pearson, P., Strudwick, T., 2005. The effects of cattle grazing on tall-herb fen vegetation and molluscs. Biological Conservation 122, 317-326.

Austin, J.E., Keough, J.R., Pyle, W.H., 2007. Effects of habitat management treatments on plant community composition and biomass in a montane wetland. Wetlands 27, 570-587.

Belanger, L., Picard, M., 1999. Cattle grazing and avian communities of the St Lawrence River Islands. Journal of Range Management 52, 332-338.

Bullock, J.M., Franklin, J., Stevenson, M.J., Silvertown, J., Coulson, S.J., Gregory, S.J., Tofts, R., 2001. A plant trait analysis of responses to grazing in a long-term experiment. Journal of Applied Ecology 38, 253-267.

Carlyle, C.N., Fraser, L.H., 2006. A test of three juvenile plant competitive response strategies. Journal of Vegetation Science 17, 11-18.

Connell, J.H., 1978. Diversity in tropical rain forests and coral reefs. Science 199 $1302-1310$.

Crosslé, K., Brock, M.A., 2002. How do water regime and clipping influence wetland plant establishment from seed banks and subsequent reproduction? Aquatic Botany 74, 43-56.

Daubenmire, R., 1970. Steppe Vegetation of Washington. Washington Agricultural Experiment Station Technical Bulletin 62. Washington State University, Pullman.

Diaz, S., Lavorel, S., McIntyre, S., Falczuk, V., Casanoves, F., Milchunas, D.G., Skarpe C., Rusch, G., Sternberg, M., Noy-Meir, I., Landsberg, J., Zhang, W., Clark, H., Campbell, B.D., 2007. Plant trait responses to grazing - a global synthesis. Global Change Biology 13, 313-341.

Diaz, S., Noy-Meir, I., Cabido, M., 2001. Can grazing response of herbaceous plants be predicted from simple vegetative traits? Journal of Applied Ecology 38, 497508 . 
Dorrough, J., Ash, J., McIntyre, S., 2004. Plant responses to livestock grazing frequency in an Australian temperate grassland. Ecography 27, 798-810.

Douglas, G.W., Straley, G.B., Meidinger, D.V., Pojar, J., 1998-2002. Illustrated Flora of British Columbia. BC Ministry of Sustainable Resource Management and BC Ministry of Forests, Victoria, BC.

Dyksterhuis, E.J., 1949. Condition and management of range land based on quantitative ecology. Journal of Range Management 2, 104-115.

Fensham, R.J., Holman, J.E., Cox, M.J., 1999. Plant species responses along a grazing disturbance gradient in Australian grassland. Journal of Vegetation Science 10, 77-86.

Frank, D., 2005. The interactive effects of grazing ungulates and aboveground production on grassland diversity. Oecologia 143, 629-634.

Fraser, L.H., Grime, J.P., 1999. Interacting effects of herbivory and fertility on synthesized plant community. Journal of Ecology 87, 514-525.

Geho, E.M., Campbell, D., Keddy, P.A., 2007. Quantifying ecological filters: the relative impact of herbivory, neighbours, and sediment on an oligohaline marsh. Oikos 116, 1006-1016.

Gough, L., Grace, J.B., 1998. Herbivore effects on plant species density at varying productivity levels. Ecology 79, 1586-1594.

Grace, J.B., 2001. The roles of community biomass and species pools in the regulation of plant diversity. Oikos 92, 193-207.

Greenwood, K.L., McKenzie, B.M., 2001. Grazing effects on soil physical properties and the consequences for pastures: a review. Australian Journal of Experimental Agriculture 41, 1231-1250.

Grime, J.P., 1973. Control of species density in herbaceous vegetation. Journal of Environmental Management 1,151-167.

Grime, J.P., 1977. Evidence for existence of three primary strategies in plants and its relevance to ecological and evolutionary theory. American Naturalist 111, 1169-1194.

Grime, J.P., 2001. Plant Strategies, Vegetation Processes, and Ecosystem Properties. John Wiley \& Sons, Inc., Chichester.

Havstad, K.M., 2008. Mongolia's rangelands: is livestock production the key to the future? Frontiers in Ecology and the Environment 7, 386-387.

Hayball, N., Pearce, M., 2004. Influences of simulated grazing and water-depth on the growth of juvenile Bolboschoenus caldwellii, Phragmites australis and Schoenoplectus validus plants. Aquatic Botany 78, 233-242.

Hendricks, H.H., Bond, W.J., Midgley, J., Novellie, P.A., 2005. Plant species richness and composition a long livestock grazing intensity gradients in a Namaqualand (South Africa) protected area. Plant Ecology 176, 19-33.

Hobbs, N.T., Baker, D.L., Bear, G.D., Bowden, D.C., 1996. Ungulate grazing in sagebrush grassland: mechanisms of resource competition. Ecological Applications 6, 200-217.

Humphrey, J., Patterson, G., 2000. Effects of late summer cattle grazing on the diversity of riparian pasture vegetation in an upland conifer forest. Journal of Applied Ecology 37, 986-996.

Johnson, W.C., Millett, B.V., Gilmanov, T., Voldseth, R.A., Gunterspergen, G.R., Naugle, D.E., 2005. Vulnerability of northern prairie wetlands to climate change. Bioscience 55, 863-872.

Kantrud, H.A., Hillar, J.B., van der Valk, A.G., 1989. Vegetation of wetlands in the Prairie Potholes Region. In: van der Valk, A.G. (Ed.), Northern Prairie Wetlands. Iowa State University Press, Ames, Iowa, pp. 132-187.

Kantrud, H.A., Stewart, R.E., 1977. Use of natural basin wetlands by breeding waterfowl in North Dakota. Journal of Wildlife Management 41, 243-253.

Kauffman, J.B., Thorpe, A.S., Brookshire, E.N.J., 2004. Livestock exclusion and belowground ecosystem responses in riparian meadows of Eastern Oregon. Ecological Applications 14, 1671-1679.

Keddy, P.A., 2000. Wetland Ecology: Principals and Conservation. Cambridge University Press, Cambridge.

Kirsch, L.M., 1969. Waterfowl production in relation to grazing. Journal of Wildlife Management 33, 821-828.

Klett, A.T., Shaffer, T.L., Johnson, D.H., 1988. Duck nest success in the Prairie Pothole Region. The Journal of Wildlife Management 52, 431-440.
Kondoh, M., 2001. Unifying the relationships of species richness to productivity and disturbance. Proceedings of the Royal Society B 268, 269-271.

Mack, R.N., Thompson, J.N., 1982. Evolution in steppe with few large, hooved mammals. American Naturalist 119, 757-773.

Manier, D.J., Hobbs, N.T., 2007. Large herbivores in sagebrush steppe ecosystems: livestock and wild ungulates influence structure and function. Oecologia 152 , 739-750.

Martin, D.W., Chambers, J.C., 2001. Effects of water table, clipping, and species interactions on Carex nebrascensis and Poa pratensis in riparian meadows. Wetlands 21, 422-430.

Marty, J.T., 2005. Effects of cattle grazing on diversity in ephemeral wetlands. Conservation Biology 19, 1626-1632.

McIntyre, S., Lavorel, S., 1994. Predicting richness of native, rare, and exotic plants in response to habitat and disturbance variables across a variegated landscape. Conservation Biology 8, 521-531.

McIntyre, S., Lavorel, S., Tremont, R.M., 1995. Plant life-history attributes - their relationship to disturbance responses in herbaceous vegetation. Journal of Ecology 83, 31-44.

Milchunas, D.G., Lauenroth, W.K., 1993. Quantitative effects of grazing on vegetation and soils over a global range of environments. Ecological Monographs 63, 327-366.

Milchunas, D.G., Sala, O.E., Lauenroth, W.K., 1988. A generalized-model of the effects of grazing by large herbivores on grassland community structure. American Naturalist 132, 87-106.

Mitsch, W.J., Gosselink, J.G., 2000. Wetlands, third ed. John Wiley \& Sons, Inc., New York.

Oksanen, J., Kindt, R., Legendre, P., O’Hara, B., Simpson, G., Solymos, P., Stevens, M., Wagner, H., 2008. Vegan: Community Ecology Package for the R Statistical Environment. Version 1.15. <http://vegan.r-forge.r-project.org>.

Olff, H., Ritchie, M.E., 1998. Effects of herbivores on grassland plant diversity. Trends in Ecology and Evolution 13, 261-265.

Pacala, S.W., Crawley, M.J., 1992. Herbivores and plant diversity. American Naturalist 140, 243-260.

Piha, H., Luoto, M., Merila, J., 2007. Amphibian occurrence is influenced by current and historic landscape characteristics. Ecological Applications 17, 2298-2309.

Pykälä, J., 2004. Cattle grazing increases plant species richness of most species trait groups in mesic semi-natural grasslands. Plant Ecology 175, 217-226.

R Development Core Team, 2008. R: and Language and Environment for Statistical Computing, Version 2.8.1. R Foundation for Statistical Computing, Vienna. $<$ http://www.R-project.org>.

Rusch, G., Oesterheld, M., 1997. Relationship between productivity, and species and functional group diversity in grazed and non-grazed Pampas grassland. Oikos 78, 519-526.

Schmutzer, A.C., Gray, M.J., Burton, E.C., Miller, D.L., 2008. Impacts of cattle on amphibian larvae and the aquatic environment. Freshwater Biology 53, 26132625.

Twolan-Strutt, L., Keddy, P.A., 1996. Above- and belowground competition intensity in two contrasting wetland plant communities. Ecology 77, 259-270.

van der Valk, A.G., 1981. Succession in wetlands: a Gleasonian approach. Ecology 62, 688-696.

van der Valk, A.G., 1986. The impact of litter and annual plants on recruitment from the seed bank of a lacustrine wetland. Aquatic Botany 24, 13-26.

van der Valk, A.G., Welling, C.H., 1988. The development of zonation in freshwater wetlands: an experimental approach. In: During, H., Werger, M., Willems, J. (Eds.), Diversity and Pattern in Plant Communities. Academic Publishing, The Hague, pp. 145-158.

Weiher, E., Keddy, P.A., 1995. The assembly of experimental wetland plant communities. Oikos 73, 323-335.

Zobel, M., 1997. The relative role of species pools in determining plant species richness: an alternative explanation of species coexistence? Trends in Ecology and Evolution 12, 266-269. 